\title{
Concentrations of osmotically related constituents in plasma and urine of finless porpoise (Neophocaena asiaeorientalis): implications for osmoregulatory strategies for marine mammals living in freshwater
}

\author{
Aihuan Guo ${ }^{1,2}$, Yujiang Hao ${ }^{1 *}$, Jingzhen Wang ${ }^{1,2}$, Qingzhong Zhao ${ }^{1}$ and Ding Wang ${ }^{1 *}$
}

\begin{abstract}
Background: Most cetaceans inhabit the hyperosmotic marine environment with only a few species living in freshwater habitats. The Yangtze finless porpoise (Neophocaena asiaeorientalis asiaeorientalis) is the only freshwater subspecies of the genus. Our aim was to study whether the osmoregulation mechanism of the Yangtze finless porpoise is different from the marine subspecies, the East Asian finless porpoise (Neophocaena asiaeorientalis sunameri). We assayed and compared the concentrations of the constituents involved in osmoregulation in the blood and urine in the Yangtze finless porpoise and the East Asian finless porpoise. We also compared the corresponding urine constituents of the porpoises with existing data on fin whales (Balaenoptera physalus) and bottlenose dolphins (Tursiops truncatus).

Results: The mean plasma osmolality of Yangtze finless porpoise was significantly lower than that of the marine subspecies $(P<0.01)$. Similarly, the urine osmolality of Yangtze finless porpoise was also significantly lower than that of its marine counterpart $(P<0.05)$. However, the urine sodium concentration of freshwater finless porpoise was significantly lower than that in the marine subspecies $(P<0.01)$, even though their serum sodium has no significant difference. Moreover, the freshwater porpoise has significantly lower urine urea concentration but much higher serum urea than in the marine finless porpoise $(P<0.05)$.

Conclusions: These results suggest that the freshwater finless porpoise does have different osmoregulatory mechanism from marine cetaceans. Conserving sodium by excreting urine with low ion levels may be an essential strategy to maintain the serum electrolyte balance for the freshwater subspecies that also appears to be more susceptible to hyponatremia.
\end{abstract}

Keywords: Finless porpoise; Osmoregulation; Plasma; Urine

\section{Background}

Based on fossil and genetic evidence, cetaceans have undergone dramatic changes during their evolutionary transformation from four-legged land animals to mammals adapted to aquatic life (Thewissen et al. 1996; Gatesy and O'Leary 2001; Gingerich et al. 2001). Today, most

\footnotetext{
*Correspondence: hao.yj@ihb.ac.cn; wangd@ihb.ac.cn

${ }^{1}$ Key Laboratory of Aquatic Biodiversity and Conservation, Institute of Hydrobiology, Chinese Academy of Sciences, 7th South Donghu Road, Wuchang District, Wuhan, Hubei 430072, People's Republic of China Full list of author information is available at the end of the article
}

cetaceans inhabit the oceans, and they are well adapted to the hyperosmotic environment. Pfeiffer (1997) reported that extant cetaceans do not appear to possess extra renal organs for salt excretion and have only a small number of anatomical modifications in the kidney. Therefore, it is likely that the aquatic ancestors of modern cetaceans relied mainly on physiological mechanisms to maintain water and electrolyte homeostasis in seawater, which is essential for the marine mammals to avoid dehydration (Ortiz 2001; Janech et al. 2002). 
Clinical examination of serum and urine can reflect the body status and health condition of the animal and may also provide essential information on their water and electrolyte homeostasis (Kjeld 2001). Blood and urine composition has been investigated in several marine cetacean species. Birukawa et al. (2005) assayed the osmoregulatory constituents in plasma and urine from common minke whales (Balaenoptera acutorostrata), sei whales (Balaenoptera borealis), Bryde's whales (Balaenoptera brydei), and sperm whales (Physeter macrocephalus), and Kjeld (2001) reported that the concentrations of various constituents in the blood and urine of fin whales (Balaenoptera physalus) related to osmoregulation. Much research has also been conducted on bottlenose dolphins (Tursiops truncatus) (Fetcher and Fetcher 1942; Malvin and Rayner 1968; Ortiz 2001; Ortiz et al. 2010; Ridgway and VennWatson 2010). Most of the results suggest that marine cetaceans may have the ability, by excreting hypertonic urine, to maintain their plasma electrolyte homeostasis to adapt to the hypertonic marine environment (Birukawa et al. 2005). However, the existing studies on cetacean osmoregulation are fairly limited, and the mechanism by which cetaceans maintain water and solute homeostasis is only partially understood (Janech et al. 2002).

Marine mammals are not normally exposed to freshwater; however, each taxonomic order of marine mammal has at least one species that exists solely in a freshwater environment (Ortiz et al. 2002). Although adapting to freshwater habitats may appear beneficial because conserving freshwater is no longer a problem, the aquatic mammals that adapt to such habitats are confronted with a different osmotic challenges. Living in a freshwater environment may require appropriate physiological mechanisms to conserve electrolytes (Ortiz 2001). The narrow-ridged finless porpoise (Neophocaena asiaeorientalis) has two subspecies in Chinese waters. The Yangtze finless porpoise (YFP, $N$. asiaeorientalis asiaeorientalis) is the sole freshwater subspecies and only inhabits the middle and lower reaches of the Yangtze River and its appended lakes (Wang 2009). The other subspecies is the East Asian finless porpoise (Neophocaena asiaeorientalis sunameri), which is widely distributed in the coastal areas of the Yellow/Bohai Seas and the northern part of the East China Sea (Jefferson and Wang 2011). Previous research suggests that the Yangtze finless porpoise originated from the marine finless porpoise (Yang et al. 2008; Zheng et al. 2005). Living in the hypotonic freshwater environment, YFP is confronted with different but equally challenging problems compared with its marine counterpart, the East Asian finless porpoise. The adaptation of two closely related subspecies to such divergent habitats provides an ideal model to understand the mechanisms of cetacean osmoregulation.
Therefore, this work aims to (1) compare the differences in osmoregulation-related constituents in the plasma and urine of freshwater and marine finless porpoise, (2) compare the freshwater and marine finless porpoise to previously published data on other cetacean species, and (3) identify the major challenges confronted by YFP and their adaptation strategies for living in the freshwater environment.

\section{Methods}

\section{Blood and urine sample collection}

We obtained 22 blood samples from 22 free-ranging YFP in the Tian-e-Zhou Reserve (E $112^{\circ} 31^{\prime}$ to $112^{\circ} 31^{\prime}$, N $29^{\circ}$ $46^{\prime}$ to $29^{\circ} 51^{\prime}$ ) in October 2010 . This reserve is the only ex situ conservation area for cetacean species in the world. It was established in 1992, and there are currently approximately 40 animals living in the reserve. In total, 22 blood samples of marine finless porpoise were collected from 15 animals represented by the Bohai Sea population (BFP), including 17 samples from 10 marine finless porpoise in Penglai Sea World, Shandong province, and 5 blood samples from 5 marine finless porpoise in Shanhaiguan Happy Ocean Park, Hebei province, China. These animals were captured accidentally by the local fisherman in the Bohai Sea and were successfully rescued and are kept in captivity by Penglai Sea World and Shanhaiguan Happy Ocean Park.

All of the animals were captured and transferred with care to a holding area for physical examination. Briefly, a $10-\mathrm{ml}$ blood sample was collected from the central vein of the tail fluke using a $10-\mathrm{ml}$ disposable syringe. Out of this sample, $4 \mathrm{ml}$ was placed in a pre-chilled EDTAtreated tube; the sample was then centrifuged for $15 \mathrm{~min}$ at 3,000 $\times g$, and the plasma was transferred to cryovials and frozen at $-20^{\circ} \mathrm{C}$ for later analysis. The remaining blood was placed in an untreated tube for $30 \mathrm{~min}$ and then centrifuged for $15 \mathrm{~min}$ at $3,000 \times g$. Finally, the serum was transferred to cryovials and frozen at $-20^{\circ} \mathrm{C}$ for future analysis.

The YFP urine samples were collected from three captive adults in Baiji Dolphinarium, Wuhan, China. These porpoises had been trained to flip onto their back and urinate voluntarily. They were mainly fed a diet of crucian carps (Carassius auratus) four times a day. The BFP urine samples were collected postmortem by direct needle aspiration from the urinary bladder of animals killed accidentally as fishing bycatch. The urine samples were transferred to cryovials and frozen at $-20^{\circ} \mathrm{C}$ for later analysis. In total, 16 YFP and 4 BFP urine samples were obtained. The study was licensed under the Regulations on the Management of Laboratory Animals, issued by the Ministry of Science and Technology of the People's Republic of China. All animal procedures were approved under the China's wild animal protective law. 


\section{Blood and urine analysis}

Plasma and urine osmolality were measured by Microosmometer Model 3300 (Advanced Instrument Inc., Norwood, MA, USA). Serum and urine electrolytes, urea, creatinine, and glucose concentrations were measured with a clinical autoanalyzer (Abbott Aeroset System Laboratories, Abbott Park, IL, USA) in Zhongnan Hospital of Wuhan University. The analyzer was calibrated with a Randox quality control product (350/2 and 223VE/1; Antrim, Northern Ireland, UK) before each assay.

The concentrations of corresponding constituents in the urine of fin whales and bottlenose dolphins were obtained from literature (Kjeld 2001; Suzuki et al. 2008) and compared with those of the freshwater and marine finless porpoise.

\section{Statistical analysis}

The serum and urine constituent data were analyzed using the descriptive statistics (mean $\pm \mathrm{SD}$ and range) in the SPSS 13.0 software (SPSS 13.0, SPSS Inc., Chicago, IL, USA). The Mann-Whitney $U$ test was used for difference analysis between YFP and BFP. Because the raw data for the other cetacean species was not available in the published literature, only the mean value and standard deviation (SD) were used for comparison with the finless porpoise.

\section{Results}

The plasma osmolality and osmoregulation-related serum constituent concentrations of freshwater and marine finless porpoise are shown in Table 1. There was no significant difference in the serum $\mathrm{Na}^{+}$observed between YFP and BFP. However, the YFP serum $\mathrm{Cl}^{-}$concentration was significantly lower than that in the BFP $(P<0.01)$. Furthermore, the serum $\mathrm{P}^{3+}$ and $\mathrm{Mg}^{2+}$ concentrations were also higher in BFP than in YFP, but no discernible difference was detected in serum $\mathrm{K}^{+}$and $\mathrm{Ca}^{2+}$ concentrations between the two subspecies. There was also no significant change in the levels of serum creatinine and glucose between YFP and BFP, while the serum urea $(P<0.05)$ and uric acid $(P<0.01)$ concentrations were significantly higher in YFP. The plasma osmolality of the YFP was much lower than that of the BFP $(P<0.01)$.

The urine osmolality and related constituents in the freshwater and marine finless porpoises are presented in Table 2. The corresponding values for fin whales and bottlenose dolphins from published research are also listed in the table for comparison. The levels of the corresponding constituents in freshwater and seawater are also presented for reference.

The concentrations of urine $\mathrm{Na}^{+}$and $\mathrm{Cl}^{-}$in YFP were significantly lower than those in BFP or the other marine cetacean species. YFP also had urinary urea concentrations significantly lower than BFP $(P<0.05)$, fin whales, or bottlenose dolphins. The urine $\mathrm{K}^{+}, \mathrm{Mg}^{2+}$, and $\mathrm{Ca}^{2+}$ concentrations were quite similar in those of the two finless porpoise populations but showed slight difference compared with those of the other marine cetaceans. There was no significant difference in the urinary creatinine concentration between YFP and BFP. The urine osmolality of the YFP was significantly lower than that of the BFP $(P<0.05)$ and that of the other two marine cetacean species.

\section{Discussion}

\section{Inorganic ions}

The concentrations of serum $\mathrm{Na}^{+}$and $\mathrm{Cl}^{-}$of toothed cetaceans are in general within a narrow range. For instance, the concentrations of serum $\mathrm{Na}^{+}$and $\mathrm{Cl}^{-}$were 156.6 and $114.3 \mathrm{mmol} / \mathrm{l}$ in harbor porpoise (Phocoena

Table 1 Plasma osmolality, serum electrolytes, and concentrations of other constituents in the Yangtze and Bohai finless porpoise

\begin{tabular}{|c|c|c|c|c|c|c|c|c|}
\hline \multirow[t]{2}{*}{ Constituents } & \multicolumn{4}{|c|}{ Yangtze population } & \multicolumn{4}{|c|}{ Bohai population } \\
\hline & $N(n)$ & Mean \pm SD & Range & CV\% & $N(n)$ & Mean \pm SD & Range & CV\% \\
\hline Osmolality mosmol/kg & $21(21)$ & $329.24 \pm 7.06$ & 317.0 to 342.0 & 2.14 & $8(8)$ & $361.5 \pm 15.2^{* *}$ & 342.0 to 387.0 & 4.20 \\
\hline $\mathrm{Na}^{+} \mathrm{mmol} / \mathrm{L}$ & $22(22)$ & $153.4 \pm 1.71$ & 149.1 to 156.4 & 1.11 & $15(22)$ & $156.24 \pm 8.11$ & 147.0 to 175.4 & 5.19 \\
\hline $\mathrm{K}^{+} \mathrm{mmol} / \mathrm{L}$ & $22(22)$ & $4.5 \pm 0.79$ & 3.64 to 7.29 & 17.56 & $15(22)$ & $4.28 \pm 0.85$ & 3.4 to 7.3 & 19.86 \\
\hline $\mathrm{Cl}^{-} \mathrm{mmol} / \mathrm{L}$ & $22(22)$ & $107.9 \pm 3.41$ & 96.80 to 111.70 & 3.16 & $15(22)$ & $117.29 \pm 7.63^{* *}$ & 106.0 to 131.70 & 6.50 \\
\hline $\mathrm{Ca}^{2+} \mathrm{mmol} / \mathrm{L}$ & $21(21)$ & $2.62 \pm 0.07$ & 2.47 to 2.77 & 2.67 & $15(22)$ & $2.53 \pm 0.25$ & 2.1 to 3.11 & 9.88 \\
\hline $\mathrm{Mg}^{2+} \mathrm{mmol} / \mathrm{L}$ & $21(21)$ & $0.7 \pm 0.11$ & 0.54 to 1.01 & 15.71 & $15(15)$ & $0.87 \pm 0.15^{* *}$ & 0.6 to 1.1 & 17.24 \\
\hline $\mathrm{P}^{3+} \mathrm{mmol} / \mathrm{L}$ & $22(22)$ & $1.26 \pm 0.26$ & 0.89 to 1.93 & 20.0 & $15(15)$ & $1.86 \pm 0.61^{* *}$ & 0.3 to 3.0 & 32.80 \\
\hline Creatinine umol/L & $22(22)$ & $81.2 \pm 11.67$ & 64.00 to 106.70 & 14.37 & $15(22)$ & $72.48 \pm 24.02$ & 41.0 to 125.2 & 33.14 \\
\hline Urea mmol/L & $20(20)$ & $16.75 \pm 3.19^{*}$ & 9.35 to 22.56 & 19.04 & $15(22)$ & $14.35 \pm 3.11$ & 9.3 to 18.6 & 21.67 \\
\hline Glucose mmol/L & $20(20)$ & $7.73 \pm 1.17$ & 5.85 to 10.37 & 15.14 & $15(15)$ & $8.31 \pm 2.27$ & 3.9 to 11.5 & 27.32 \\
\hline Uric acid umol/L & $22(22)$ & $44.6 \pm 17.14^{* *}$ & 22.80 to 84.20 & 38.43 & $15(22)$ & $12.94 \pm 7.98$ & 4.3 to 36.0 & 61.67 \\
\hline
\end{tabular}

Significant differences between the finless porpoises are indicated by ${ }^{*} P<0.05$ and ${ }^{* *} P<0.01 . \mathrm{N}$, individual number; $\mathrm{n}$, sample number. 
Table 2 Osmolality and other constituent values in urine of finless porpoise compared with other cetacean species

\begin{tabular}{|c|c|c|c|c|c|c|c|c|}
\hline \multirow[t]{2}{*}{ Constituents } & \multirow[t]{2}{*}{ Fin whale ${ }^{a}$} & \multirow[t]{2}{*}{ Bottlenose dolphin ${ }^{b}$} & \multirow[t]{2}{*}{ Freshwater ${ }^{c}$} & \multirow[t]{2}{*}{ Seawater $^{\mathrm{d}}$} & \multicolumn{2}{|c|}{ Yangtze population } & \multicolumn{2}{|c|}{ Bohai sea population } \\
\hline & & & & & $N(n)$ & Mean \pm SD & $N(n)$ & Mean \pm SD \\
\hline $\mathrm{Na}^{+} \mathrm{mmol} / \mathrm{L}$ & $303.0 \pm 56.6$ & $490.1 \pm 87.9$ & 0.35 & 470 & $3(15)$ & $20.07 \pm 8.13$ & $4(4)$ & $156.95 \pm 77.33^{* *}$ \\
\hline $\mathrm{Cl}^{-} \mathrm{mmol} / \mathrm{L}$ & $306.0 \pm 57.5$ & $402.7 \pm 79.6$ & 0.23 & 548 & $3(15)$ & $13.0 \pm 5.38$ & $4(4)$ & $194.15 \pm 76.92^{* *}$ \\
\hline $\mathrm{K}^{+} \mathrm{mmol} / \mathrm{L}$ & $60.9 \pm 21.3$ & $80.7 \pm 25.8$ & 0.08 & 10 & $3(16)$ & $65.5 \pm 12.14$ & $4(4)$ & $60.55 \pm 12.49$ \\
\hline $\mathrm{Ca}^{2+} \mathrm{mmol} / \mathrm{L}$ & - & - & 0.75 & 10 & $3(16)$ & $2.4 \pm 0.72$ & $4(4)$ & $3.35 \pm 2.16$ \\
\hline $\mathrm{Mg}^{2+} \mathrm{mmol} / \mathrm{L}$ & $19.4 \pm 6.2$ & - & 0.21 & 54 & $3(16)$ & $2.2 \pm 0.62$ & $4(4)$ & $2.21 \pm 1.64$ \\
\hline Creatinine mmol/L & $4.3 \pm 3.07$ & $8.5 \pm 5.0$ & - & - & $3(16)$ & $2.6 \pm 0.89$ & $4(4)$ & $3.2 \pm 1.79$ \\
\hline Urea mmol/L & $419.0 \pm 186.0$ & $703.5 \pm 253.9$ & - & - & $3(4)$ & $40.7 \pm 15.78$ & $4(4)$ & $74.96 \pm 20.06^{*}$ \\
\hline Osmolality mosmol/kg & $1040 \pm 211.0$ & $1715.7 \pm 279.4$ & - & $1,000^{\mathbf{b}}$ & $3(14)$ & $934.6 \pm 149.99$ & $4(4)$ & $1223.75 \pm 341.84^{*}$ \\
\hline
\end{tabular}

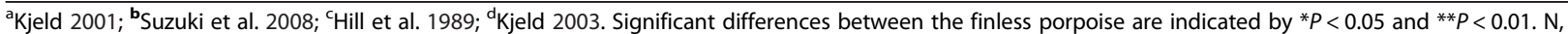
individual number; $\mathrm{n}$, sample number.

phocoena) (Koopman et al. 1995) and 156 and $113 \mathrm{mmol} /$ 1 in Atlantic bottlenose dolphins (T. truncatus) (Fair et al. 2006), respectively. This implies that these serum electrolytes play an important role in maintaining the homeostasis of body fluid and physiological functions. However, serum electrolyte levels may be affected by diet and habitat. It is thought that marine mammals obtain water and electrolytes mainly from their food (Costa 2002). When bottlenose dolphins were exposed to seawater and highprotein meals, their serum sodium, chloride, and potassium levels were temporarily elevated (Ridgway and Venn-Watson 2010). Furthermore, captive and wild West Indian manatees (Trichechus manatus) living in freshwater were found to have significantly lower plasma $\mathrm{Na}^{+}$, $\mathrm{K}^{+}$, and $\mathrm{Cl}^{-}$levels than wild manatees living in brackish and saltwater (Ortiz et al. 1998). Similarly, the Amazon River dolphin (Inia geoffrensis) was also reported to have lower $\mathrm{Na}^{+}, \mathrm{Cl}^{-}$, and $\mathrm{K}^{+}$values than marine cetaceans (Ridgway et al. 1970). Therefore, based on these previous studies, it would be expected that the relatively low serum $\mathrm{Cl}^{-}, \mathrm{Mg}^{2+}$, and $\mathrm{P}^{3+}$ concentrations found in YFP, compared with BFP, were caused by their environmental and dietary differences. However, interestingly, no significant difference in serum $\mathrm{Na}^{+}$levels was found between YFP and BFP, even though their osmotic environment is entirely different, which suggests the importance of the relatively stable serum natrium in the freshwater porpoise.

There are no exocrine glands in the skin of cetaceans to excrete electrolytes (Ridgway 1972). Therefore, the urinary electrolyte levels are likely to reflect their food intake from their prey to a large extent (Kjeld 2001). The urine $\mathrm{Na}^{+}$and $\mathrm{Cl}^{-}$concentrations in YFP were much lower than those in BFP, fin whales or bottlenose dolphins. The YFP, living in freshwater and feeding on small freshwater fish species, is exposed to less salt than the marine mammals. This makes YFP, and especially the captive animals, more susceptible to hyponatremia than their marine counterparts. The extremely low $\mathrm{Na}^{+}$ and $\mathrm{Cl}^{-}$in the urine samples of the captive YFP may imply that it is important for the animals inhabiting freshwater to conserve their sodium to keep their blood sodium balance. In fact, this has also been reported in some pinnipeds kept in freshwater facilities (Geraci 1972).

\section{Organic solutes}

Urea is a product of nitrogen compound proteins and amino acids and plays a key role in the urineconcentrating mechanism in mammals (Sands 2002). As a small molecular product of protein metabolism production, urea is easily dissolved in water, which makes it a water-conserving nitrous product excreted in urine (Knepper and Mindell 2009). This may be particularly significant for the marine cetaceans, considering the saline environment they inhabit.

The urea concentration of urine is considered to be related to high-protein food. For example, ingesting a high protein and fat diet may increase the urea concentration of urine in bottlenose dolphins (Ridgway and VennWatson 2010). Similar results were also found in harbor seals (Phoca vitulina) (Schmidt-Nielsen et al. 1959). Interestingly, YFP had higher serum urea but much lower urine urea than the marine finless porpoise. Since both freshwater and marine porpoise are mainly fed on fish, this cannot be ascribed to dietary differences, even though they may prey on different species of fish. The significantly lower urine and higher serum urea in YFP, compared with BFP and other marine cetaceans, may indicate that freshwater porpoise need to retain the urea in their body fluid. This suggests that serum urea may have a function in regulating the osmotic pressure of blood.

Previous research has shown that baleen whales have significantly higher concentrations of urea in plasma and urine than the terrestrial cattle, which suggests that urea may be used to maintain the body fluid of cetaceans (Birukawa et al. 2005). Other studies have also suggested that cetaceans can maintain their body fluid osmotic 
pressure by reabsorbing urea through their kidney (Birukawa et al. 2008; Janech et al. 2002), the main organ regulating urea excretion. Approximately $25 \%$ to $40 \%$ of filtered urea is reabsorbed in the renal tubules (Bossart et al. 2001), which may be regulated by changes in the urea transporter types and the functions of cetacean kidneys (Janech et al. 2002). The significant difference in serum and urine urea levels between the freshwater and marine finless porpoise may indicate different osmoregulation mechanisms in the two distinct porpoise subspecies. Therefore, this warrants further comparative investigation of urea reabsorption in the kidneys of the YFP and BFP to further understand the osmoregulatory divergence of the two finless porpoise subspecies.

Uric acid is a product of purine metabolism (Ridgway et al. 1970). In this study, the freshwater porpoise had higher serum uric acid levels compared to the marine subspecies $(P<0.05)$. The serum uric acid in Amazon River dolphin (about $600 \mu \mathrm{mol} / \mathrm{L}$ ) was also found to be higher than those of some small marine odontocetes (Ridgway et al. 1970). However, the serum uric acid can be influenced by stress, high dietary purine, and renal disease (Daniels 2003). More research is therefore needed to be able to conclude whether the serum uric acid concentration plays a role in osmoregulation in freshwater cetaceans.

\section{Osmotic pressure balance}

The plasma osmolalities in YFP and BFP both kept in relatively narrow range with pretty low CVs $(2.14 \%$ and $4.2 \%$ for freshwater and marine captive finless porpoise, respectively), which may indicate the importance of osmotic homeostasis for their body fluid. Bottlenose dolphins can maintain their plasma osmotic homeostasis by excreting urine with variable osmolalities (Ridgway and Venn-Watson 2010). This has also been demonstrated in other cetacean species (Malvin and Rayner 1968). Moreover, West Indian manatees can also regulate their plasma osmolalities in relatively narrow range over a broad range of environmental salinities (Ortiz et al. 1998). The distinct but relatively stable plasma osmolalities in the respective finless porpoise subspecies is much likely to be a result of adaptation to their different osmotic environments. Moreover, the plasma osmolality of bottlenose dolphin can so be changed in a certain range when they were fed with different types of fish species (Skog and Folkow 1994; Ortiz 2001). Therefore, the significantly high plasma osmolality in marine finless porpoise than in the Yangtze finless porpoise may be also partly due to their diet difference in captivity, which definitely needs further detailed investigations.

The urine osmolality of YFP was found to be statistically lower than that of the BFP and that of the other cetaceans, which may be an important strategy for the freshwater porpoise to conserve electrolytes and for the marine subspecies to conserve their body water content. In fact, based on previous findings, it is not surprising to see that marine cetaceans produce concentrated urine to preserve water and maintain osmotic balance in their body fluid (Ortiz 2001; Birukawa et al. 2005). However, the osmotic pressure of some YFP urine samples can reach higher than 1,000 mosM (Table 2), which indicates that YFP can also excrete highly concentrated urine but, interestingly, without much higher $\mathrm{Na}^{+}$and $\mathrm{Cl}^{-}$concentrations. Unlike the other freshwater vertebrates, such as teleost fish, lampreys, and frogs, it seems that it is not necessary for YFP to deliberately produce super hypoosmotic urine to void excess water (Hill et al. 1989). Drinking water does not appear to be a common way for cetaceans and pinnipeds to obtain water (Fetcher and Fetcher 1942; Ortiz 2001), and similarly, YFP may also mainly acquire water from their food and via their metabolism. Therefore, YFP may not have as much of a need to excrete excess water as the other lower aquatic vertebrates. Because the major urine electrolyte concentrations in YFP are generally much lower compared with those in the marine subspecies, the significant osmolality variation in the urine of freshwater porpoise may be determined mainly by the organic constituents and influenced by their diet.

\section{Conclusions}

YFP and BFP are two porpoise subspecies living in osmotically distinct environments. Their differences in serum electrolyte and osmotic blood homeostasis suggest that they may have divergent osmoregulation strategies to adapt to their distinct environments. Based on our findings, conserving serum sodium appears to be essential for the freshwater porpoise. Conversely, excreting highly concentrated urine with much higher sodium and chloride content is the major strategy for the marine porpoise to release their hypertonic burden. Furthermore, serum urea appears to play an important role in maintaining the blood osmolality homeostasis in the freshwater finless porpoise. They have much higher serum urea but much lower urine urea than their marine counterpart. This study helps to shed light on the adaptation divergence of the finless porpoise in osmotically different habitats. It also suggests that further morphological and physiological investigation is needed on the osmoregulation adaptation mechanisms in these two ecologically different subspecies of finless porpoise.

\section{Competing interests}

The authors declare that they have no competing interests.

\section{Authors' contributions}

YH and DW designed and conceived the experiment. QZ, YH, and AG carried out all the sampling. AG and $\mathrm{YH}$ performed the data analysis. $\mathrm{AG}, \mathrm{YH}$, and JW wrote the paper. All authors read and approved the final manuscript. 


\section{Acknowledgments}

We are grateful to the staff of the Tian-e-Zhou Reserve, Director Liang-Hui $\mathrm{Hu}$, and Dao-Bin Gao for facilitating the capture of Yangtze finless porpoise and the staff of our research group for the sample collection. We also thank the staff of Penglai Sea World and Shanhaiguan Happy Ocean Park for collecting the samples of marine finless porpoise. We also express our sincere gratitude to the Zhongnan Hospital for the sample assay. This work was funded by the Knowledge Innovation Program of the Chinese Academy of Sciences (No. KSCX2-EW-Z-4).

\section{Author details}

${ }^{1}$ Key Laboratory of Aquatic Biodiversity and Conservation, Institute of Hydrobiology, Chinese Academy of Sciences, 7th South Donghu Road, Wuchang District, Wuhan, Hubei 430072, People's Republic of China. ${ }^{2}$ University of Chinese Academy of Sciences, Beijing 100864, China.

Received: 3 September 2013 Accepted: 6 February 2014 Published: 12 February 2014

\section{References}

Birukawa N, Ando H, Goto M, Kanda N, Pastene LA, Nakatsuji H, Hata H, Urano A (2005) Plasma and urine levels of electrolytes, urea and steroid hormones involved in osmoregulation of cetaceans. Zool Sci 22(11):1245-1257

Birukawa N, Ando H, Goto M, Kanda N, Pastene LA, Urano A (2008) Molecular cloning of urea transporters from the kidneys of baleen and toothed whales. Comp Biochem Physiol B Biochem Mol Biol 149:227-235

Bossart GD, Reidarson TH, Dierauf LA, Duffield DA (2001) Clinical pathology. In: CRC handbook of marine mammal medicine. CRC, Boca Raton

Costa D (2002) Osmoregulation. In: Encyclopedia of marine mammals. Academic Press, New York

Daniels R (2003) Delmar's manual of laboratory and diagnostic tests. Thomson Learning Inc, Delmar

Fair PA, Hulsey TC, Varela RA, Goldstein JD, Adams J, Zolman ES, Bossart GD (2006) Hematology, serum chemistry, and cytology findings from apparently healthy Atlantic bottlenose dolphins (Tursiops truncatus) inhabiting the estuarine waters of Charleston, South Carolina. Aquat Mamm 32(2):182

Fetcher E, Fetcher GW (1942) Experiments on the osmotic regulation of dolphins. J Cell Comp Physiol 19(1):123-130

Gatesy J, O'Leary MA (2001) Deciphering whale origins with molecules and fossils. Trends Ecol Evol 16(10):562-570

Geraci JR (1972) Hyponatremia and the need for dietary salt supplementation in captive pinnipeds. J Am Vet Med Assoc 161(6):618-623

Gingerich PD, Haq M, Zalmout IS, Khan IH, Malkani MS (2001) Origin of whales from early artiodactyls: hands and feet of Eocene Protocetidae from Pakistan. Science 293(5538):2239-2242

Hill RW, Wyse GA, Anderson M (1989) Animal physiology, 2nd edn. Harper Collins Publishers, New York

Janech MG, Chen R, Klein J, Nowak MW, McFee W, Paul RV, Fitzgibbon WR, Ploth DW (2002) Molecular and functional characterization of a urea transporter from the kidney of a short-finned pilot whale. Am J Physiol Regul Integr Comp Physiol 282(5):R1490-R1500

Jefferson TA, Wang JY (2011) Revision of the taxonomy of finless porpoises (genus Neophocaena): the existence of two species. J Mar Anim Ecol 4(1):3-16

Kjeld M (2001) Concentrations of electrolytes, hormones, and other constituents in fresh postmortem blood and urine of fin whales (Balaenoptera physalus). Can J Zool 79(3):438-446

Kjeld M (2003) Salt and water balance of modern baleen whales: rate of urine production and food intake. Can J Zool 81(4):606-616

Knepper MA, Mindell JA (2009) Structural biology: molecular coin slots for urea. Nature 462(7274):733-734

Koopman H, Westgate A, Read A, Gaskin D (1995) Blood chemistry of wild harbor porpoises Phocoena phocoena (L.). Mar Mamm Sci 11(2):123-135

Malvin RL, Rayner M (1968) Renal function and blood chemistry in Cetacea. Am J Physiol 214(1):187-191

Ortiz RM (2001) Osmoregulation in marine mammals. J Exp Biol 204(11):1831-1844

Ortiz RM, Worthy GAJ, Mackenzie DS (1998) Osmoregulation in wild and captive West Indian manatees (Trichechus manatus). Physiol Zool 71(4):449-457

Ortiz RM, Wade CE, Costa DP, Ortiz CL (2002) Renal effects of fresh water-induced hypo-osmolality in a marine adapted seal. J Comp Physiol B 172(4):297-307
Ortiz RM, Long B, Casper D, Ortiz CL, Williams TM (2010) Biochemical and hormonal changes during acute fasting and re-feeding in bottlenose dolphins (Tursiops truncatus). Mar Mamm Sci 26(2):409-419

Pfeiffer C (1997) Renal cellular and tissue specializations in the bottlenose dolphin (Tursiops truncatus) and beluga whale (Delphinapterus leucas). Aquat Mamm 23:75-84

Ridgway S (1972) Homeostasis in the aquatic environment. In: Mammals of the sea: biology and medicine. CC Thomas, Springfield

Ridgway S, Venn-Watson S (2010) Effects of fresh and seawater ingestion on osmoregulation in Atlantic bottlenose dolphins (Tursiops truncatus). J Comp Physiol B 180(4):563-576

Ridgway S, Simpson J, Patton G, Gilmartin W (1970) Hematologic findings in certain small cetaceans. J Am Vet Med Assoc 157(5):566-575

Sands JM (2002) Molecular approaches to urea transporters. J Am Soc Nephrol 13(11):2795-2806

Schmidt-Nielsen B, Murdaugh H, O'Dell R, Bacsanyi J (1959) Urea excretion and diving in the seal (Phoca vitulina L.). J Cell Comp Physiol 53(3):393-411

Skog E, Folkow L (1994) Nasal heat and water exchange is not an effector mechanism for water balance regulation in grey seals. Acta Physiol Scand 151(2):233-240

Suzuki M, Endo N, Nakano Y, Kato H, Kishiro T, Asahina K (2008) Localization of aquaporin-2, renal morphology and urine composition in the bottlenose dolphin and the baird's beaked whale. J Comp Physiol B 178:149-156

Thewissen JGM, Roe LJ, ONeil JR, Hussain ST, Sahni A, Bajpal S (1996) Evolution of cetacean osmoregulation. Nature 381(6581):379-380

Wang D (2009) Population status, threats and conservation of the Yangtze finless porpoise. Chin Sci Bull 54(19):3473-3484

Yang G, Guo L, Bruford MW, Wei F, Zhou KY (2008) Mitochondria phylogeography and population history of finless porpoises in Sino-Japanese waters. Biol J Linn Soc 95(1):193-204

Zheng JS, Xia JH, He SP, Wang D (2005) Population genetic structure of the Yangtze finless porpoise (Neophocaena phocaenoides asiaeorientalis): implications for management and conservation. Biochem Genet 43(5-6):307-320

\section{doi:10.1186/1810-522X-53-10}

Cite this article as: Guo et al:: Concentrations of osmotically related constituents in plasma and urine of finless porpoise (Neophocaena asiaeorientalis): implications for osmoregulatory strategies for marine mammals living in freshwater. Zoological Studies 2014 53:10.

\section{Submit your manuscript to a SpringerOpen ${ }^{\circ}$ journal and benefit from:}

- Convenient online submission

- Rigorous peer review

- Immediate publication on acceptance

- Open access: articles freely available online

- High visibility within the field

- Retaining the copyright to your article

Submit your next manuscript at springeropen.com 